\title{
Fábrica de Reciclagem: Uma Abordagem para o Auxiliar no Ensino e Conscientização sobre Coleta Seletiva
}

\author{
Christian R. Costa ${ }^{1}$, Rubber Rodriguez ${ }^{1}$, Bruno A. Bonifácio ${ }^{1}$, Odette Mestrinho \\ Passos $^{1}$, Elias Neto ${ }^{2}$ Priscila S. Fernandes ${ }^{3}$ \\ ${ }^{1}$ Instituto de Ciências Exatas e Tecnologia -ICET - UFAM, Itacoatiara - \\ Caixa Postal 15.064 - 91.501-970 - Amazonas - Brasil
}

${ }^{2}$ Universidade Nilton Lins - Manaus - Caixa Postal 3259 - 69.058-030 - Amazonas Brasil

${ }^{3}$ Grupo de Usabilidade e Engenharia de Software - USES, ICOMP-UFAM, Manaus, Amazonas.

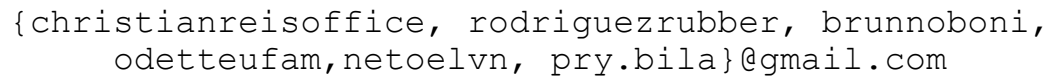

\begin{abstract}
Resumo. Por ser parte da sociedade e corresponsável pela sua transformação, a Escola precisa oferecer meios para estimular a consciência crítica e comprometida dos alunos com o meio ambiente. Diante disso, o uso de jogos pode criar alternativas para trabalhar a consciência social e facilitar o aprendizado. Este trabalho apresenta um jogo, chamado Fábrica de Reciclagem, que pode ser aplicado para o ensino de crianças, no contexto de ciências ambientais. Através das analogias o jogo permite trabalhar conceitos de lógica à medida que ensina sobre descarte correto de lixo. No jogo, o usuário é instigado a calcular a localização correta do lixo para envio sobre as esteiras e obstáculos, tornando o jogo interessante.
\end{abstract}

\section{Cenário de uso}

A produção de resíduos sólidos tem aumentado consideravelmente, no mundo moderno, causando vários problemas ao ambiente e à saúde pública (Li e Chen, 2013). Com o crescimento populacional, várias entidades têm se preocupado com o descarte correto dos resíduos produzidos (Trindade, 2011). Por essa razão, o gerenciamento correto do lixo representa hoje um tema bastante complexo.

Devido à falta de destinação correta dos resíduos, a educação ambiental é fundamental para preservação do nosso planeta. Por essa razão, a criação de tecnologias sociais pode fornecer uma importante contribuição para o gerenciamento dos resíduos produzidos (Brasil et al., 2004). Nesse contexto, a coleta seletiva pode exercer uma importante iniciativa para preservação do meio ambiente. Por razões culturais, o ser humano é resistente a tornar a reciclagem uma prática habitual. No entanto, estabelecer políticas de conscientização e educação ambiental pode facilitar o manejo adequado do lixo e dos resíduos, evitando custos elevados com parte do saneamento básico.

Dessa forma, abordar a problemática da produção e destinação do lixo, por meio de coleta seletiva, no processo de educação é um desafio (Aguiar,1993). Assim, a escola deve oferecer meios para que seus alunos participem e se manifestem, criando sua 
consciência crítica e comprometida com o meio ambiente, especialmente na educação infantil. As aulas de arte e ciências são muito boas para fazer essa iniciação, pois é possível trabalhar conceitos de conscientização e coleta através de cores, desenvolvimento de ações e projetos para engajar as crianças, que posteriormente pode influenciar os pais e responsáveis.

Diante desse cenário, o ensino de forma lúdica pode criar uma experiência de aprendizado inovadora. Assim, jogos educativos podem fornecer uma importante contribuição, no processo de aprendizagem. Esse contexto motivou a elaboração do jogo para dispositivos móveis, chamado Fábrica de Reciclagem. Essa solução utiliza uma abordagem de interação que visa melhorar a experiência de ensino, como prática inovadora. Para isso, utiliza formas de interação que permite trabalhar aspectos de aprendizagem, baseado em lógica além de sensibilização-conscientização.

O Fábrica de Reciclagem pode ser aplicado para educação infantil, como prática pedagógica, a fim de despertar nos alunos, a consciência ambiental necessária para que estes entendam a importância da coleta seletiva, e a gerenciar adequadamente a coleta dos resíduos e lixos, produzidos na sua comunidade. Além disso, o Fábrica de Reciclagem utiliza uma abordagem de lógica que permite estimular as crianças a estabelecer formas de como realizar a coleta da melhor forma possível, dentro do jogo.

\section{Desenvolvimento}

Com a relevância dada nos últimos anos para questões ambientais, a população precisa desenvolver consciência ecológica. Nesse contexto, a Escola deve oferecer meios para que seus alunos participem e sejam estimuladas para criar consciência crítica e comprometida com o meio ambiente. Assim, os educadores têm papel fundamental na inserção de práticas de ensino que estimulem o aprendizado e a importância da educação ambiental.

Diante desse cenário, os jogos podem ser uma importante ferramenta de aprendizado. Por essa razão, optou-se por desenvolver um jogo que pudesse criar um cenário construtivista. $\mathrm{O}$ propósito foi incentivar a conscientização sobre os cuidados com o descarte correto do lixo, e, estimular a atenção dos alunos através de atividades de competição e cooperação, com regras bem definidas.

Nesse contexto, o Fábrica de Reciclagem visa estimular um ambiente de aprendizado que trabalha não só a sensibilização para questões de coleta seletiva, como desafios que visam motivar os usuários do jogo. Para isso, ele foi elaborado considerando etapas, com grau de dificuldade gradual. No jogo, o usuário precisa encontrar alternativas para descartar o lixo corretamente, a medida que aprende sobre quais as cores correspondentes para cada tipo de resíduo. A Figura 1 apresenta a interface inicial do jogo. 


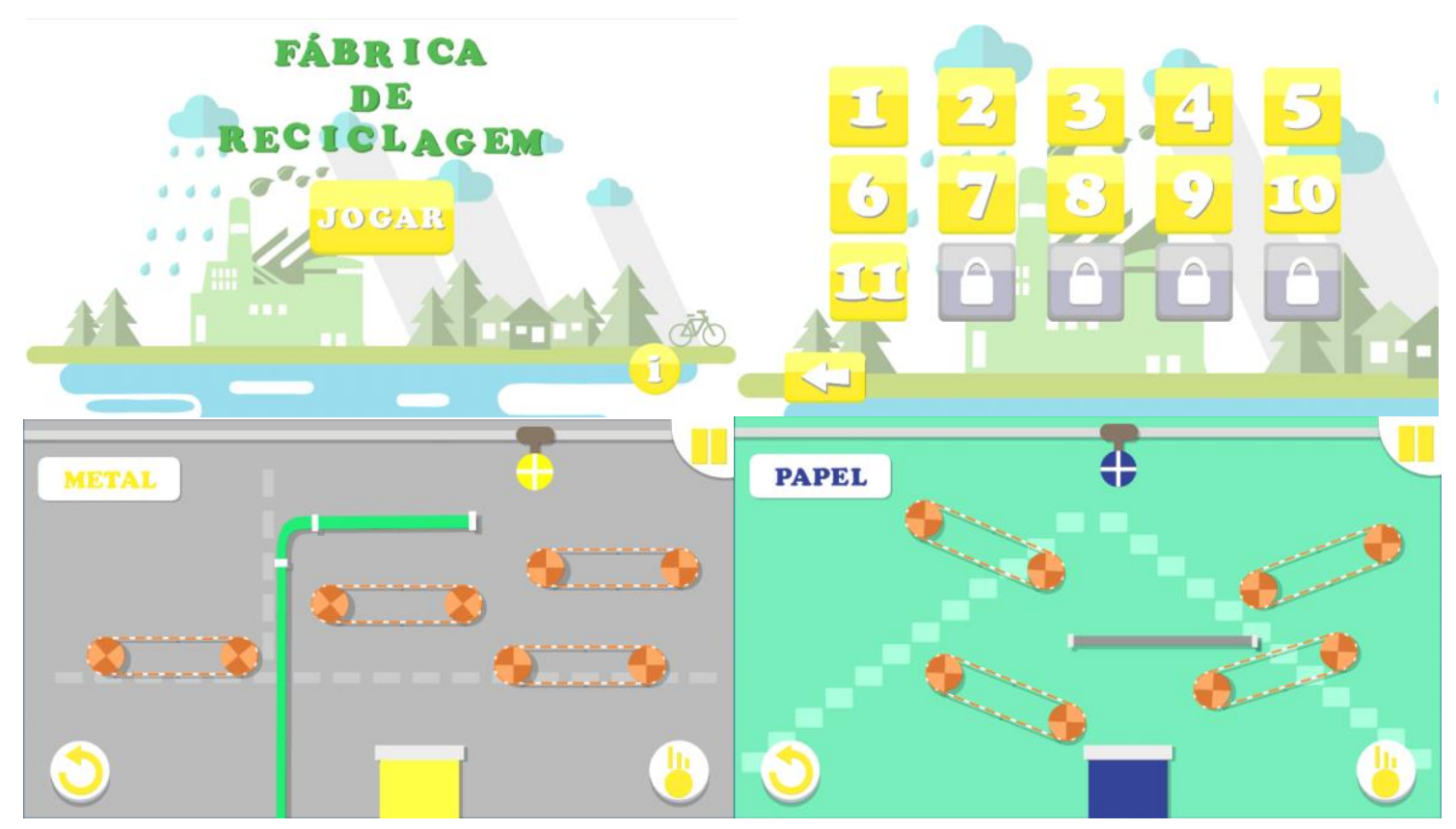

Figura 1. Interface Gráfica do Aplicativo Fábrica de Reciclagem.

O jogo apresenta um total de 15 fases e consiste em posicionar o resíduo, que possui cores correspondentes para cada tipo de resíduo, com o objetivo de descartar nas lixeiras (Figura 1). Assim, para que o resíduo percorra o caminho até o lixo correspondente, o mesmo precisa deslizar sobre as esteiras, que possuem direções diferentes. Por essa razão, o usuário precisa identificar a posição correta para descartar o lixo, caso contrário o lixo cairá fora da lixeira e o usuário perde o jogo. A versão inicial do aplicativo está disponível na loja de aplicativos do Google, Play Store ${ }^{1}$.

A tecnologia utilizada para o desenvolvimento do jogo foi o Unity, utilizando a linguagem C\#. Para a criação de imagens e gráficos usando o CorelDRAW. A Unity é uma plataforma de desenvolvimento que permite a criação de jogos tridimensionais (Brito et al., 2016). Através da Unity é possíel a criação de jogos para diversas plataformas, como android, iphone e sistemas windows, Mac e Web. Outra característica vantajosa para a escolha da Unity são os recursos da plataforma, que permite a visualização de todas as cenas do jogo, manipular objetos contidos nas cenas e a física que compõe o objeto (Li e Cheng, 2013).

Para validação inicial do jogo foi feito um teste de usabilidade com dez crianças de oito a 12 anos. O objetivo da avaliação foi estimular as crianças no aprendizado da importância da coleta seletiva e do descarte correto de resíduos. O jogo apresenta dicas e curiosidades sobre coleta seletiva. Após a utilização do jogo as crianças e responsáveis foram encorajados a dar o feedback sobre a interação com o jogo. Além da satisfação de uso. Para coleta dos dados foi utilizado o SAM (Self-Assessment Manikin). O método SAM utiliza avaliação ilustrada não-verbal, com o propósito de medir diretamente a satisfação, estimulo e dominância associada com a reação afetiva de uma pessoa (Bradley e Lang, 1994).

\footnotetext{
${ }^{1}$ Link de download do jogo: googleplay.com/fabrica
} 
VI Congresso Brasileiro de Informática na Educação (CBIE 2017)

Anais dos Workshops do VI Congresso Brasileiro de Informática na Educação (WCBIE 2017)

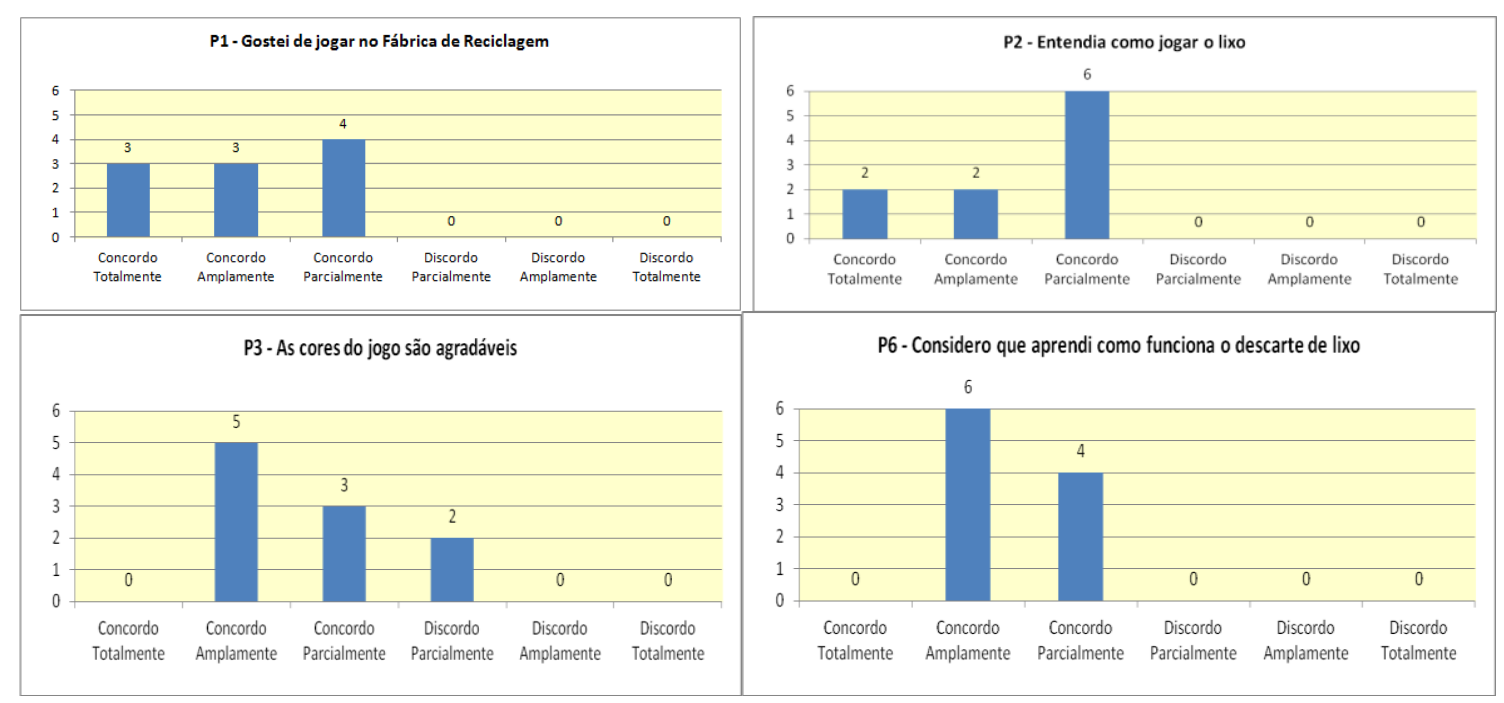

Figura 2. Resultados sobre a satisfação de uso do Fábrica de Reciclagem.

Os resultados foram úteis para aprimorar o jogo e divulgar nas redes sociais. Os resultados mostram valores favoráveis ao uso. Além disso, foi feita uma análise qualitativa, que permitiu coletar informações úteis sobre os conceitos e a jogabilidade do Fábrica de Reciclagem. A utilização de posições e elementos da física, para o descarte correto pode permitir trabalhar melhor conceitos relacionados ao aprendizado de outras disciplinas.

Algumas percepções foram capturadas através de entrevistas com os participantes. Os resultados mostraram grande impacto que o jogo pode ter na educação ambiental. O participante 1, por exemplo, relata "Sempre confundia as lixeiras, mesmo com as cores. Agora após o jogo o reconhecimento se torna automático." Outro ponto identificado foi em relação a abordagem do jogo, que usa posições para o envio do resíduo, conforme também relata o participante 1 "Enviar os lixos na posição correta, para que ele deslize na esteira deixa o jogo emocionante, principalmente quando perdemos." ou ainda a percepção de quem teve maior dificuldade, como o participante 3 "Gostei da música, fico mais empolgado ao ouvir ela. Me deixa mais nervoso para soltar o lixo, emocionante.". Apesar das percepções positivas em relação ao jogo, muitos participantes relataram algumas limitações.

As limitações identificadas foram em relação as fases, pois o jogo possui apenas 15 fases no nível iniciante. Tal limitação já está sendo minimizada para a construção da próxima versão. Além disso, um dos participantes relatou, como limitação, a interface, como "O lixo não parece lixo, na imagem. Depois que imaginei ele deixado que fica redondinho. Seria bom redesenhar!". Ou ainda o relato do participante 7 "As cores são bem legais. Mas precisa diversificar, adicionar uns monstros para dificultar mais, outro nivel mais avançado". Vale salientar que os dados coletados foram feitos, por meio de entrevistas, com o teste gravado por câmera sob autorização dos pais e responsáveis pelas crianças. 
VI Congresso Brasileiro de Informática na Educação (CBIE 2017)

Anais dos Workshops do VI Congresso Brasileiro de Informática na Educação (WCBIE 2017)

\section{Apresentação do Software}

O Fábrica de Reciclagem está disponível na loja do Google, e pode ser visualizado também no Youtube ${ }^{2}$. O objetivo do jogo é realizar o descarte correto do resíduo. Cada resíduo apresenta cores, conforme o tipo do resíduo. A Figura 3 apresenta a interface do jogo.

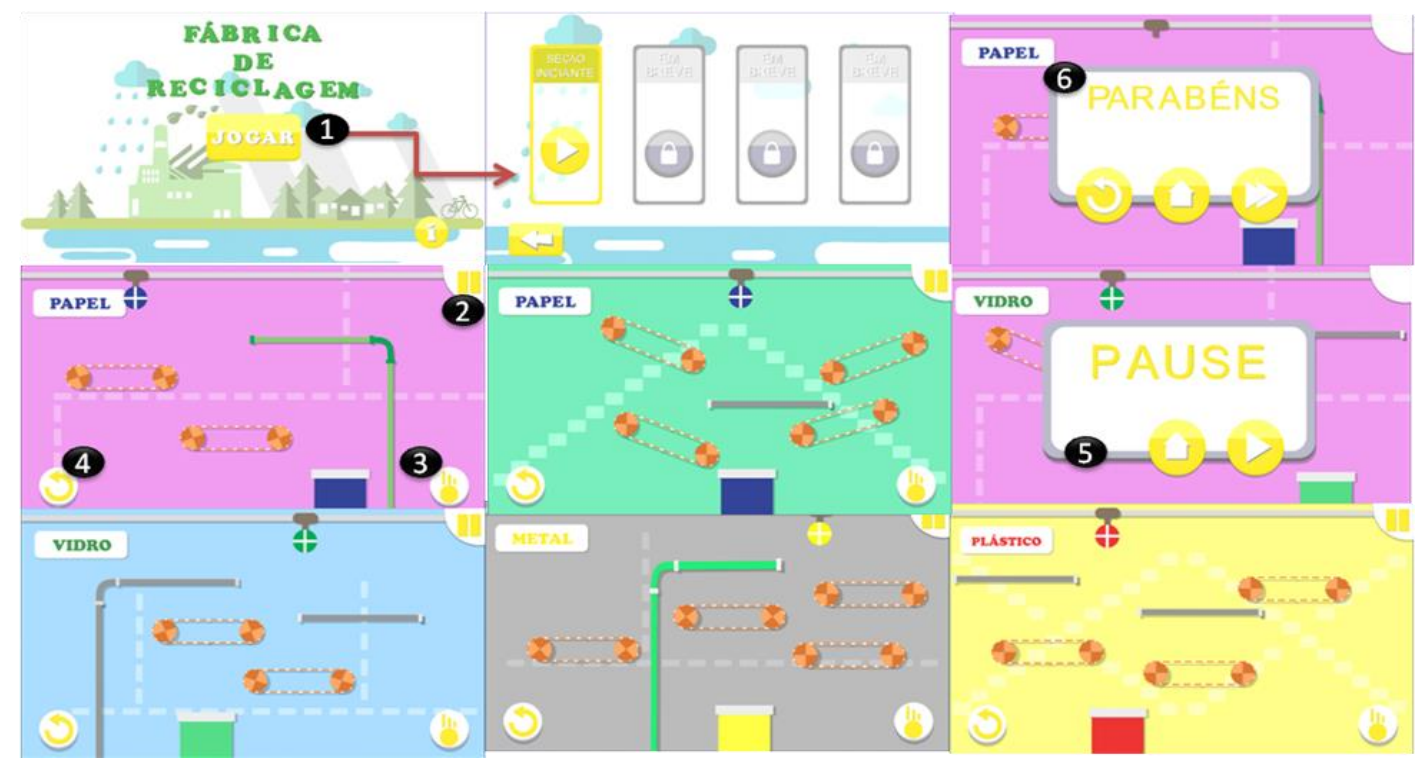

Figura 3. Interfaces do jogo Fábrica de Reciclagem

A aplicação inicia com o botão de jogar (item 1) e uma tela para informação. Para cada item o jogo possui níveis de dificuldade, que na versão inicial possui apenas o nível iniciante. Após selecionar o jogo mostra uma tela com diversos componentes. A analogia utilizada foi de uma fábrica, com esteiras que levam diretamente ao lixo.

O usuário poderá segurar e soltar o lixo (item 3) para que o mesmo seja levado pelas esteiras. Após cada etapa o jogo vai transmitindo conceitos relacionados a coleta seletiva. A medida que o usuário vai interagindo o jogo aumenta a dificuldade. Para melhor organizar a jogabilidade o usuário pode pausar a aplicação (item 2) ou ainda voltar os níveis (item 4).

\section{Considerações finais}

O presente trabalho apresenta um jogo, chamado Fábrica de Reciclagem. O jogo pode ser aplicado para o ensino de crianças, no contexto de ciências e meio ambiente. Através das analogias o jogo também permite trabalhar conceitos de lógica. No jogo o usuário é instigado a calcular a localização correta do lixo para envio sobre as esteiras que possuem direções diferentes para dificultar e tornar o jogo mais interessante.

Por se tratar de assunto relacionado a itens ambientais as crianças começam a aprender a importância da reciclagem na escola através e podem usar o jogo como

\footnotetext{
2 Vídeo de divulgação do Fábrica: https://youtu.be/whKDPZBlHrs
} 
VI Congresso Brasileiro de Informática na Educação (CBIE 2017)

Anais dos Workshops do VI Congresso Brasileiro de Informática na Educação (WCBIE 2017)

complemento para o aprendizado. Além disso, é possível ser utilizada em aulas de artes, já que pode ser aplicado junto com a criação de materiais de reciclagem.

Espera-se com isso, mostrar a importância da área ambiental, podendo ser aplicado a diversas outras como a Engenharia Sanitária associada aos conteúdos de administração, da economia e áreas afins. Além de ensinar e divulgar mais conteúdo para permitir que as crianças e adultos aprendam mais sobre o assunto e com certeza criar um modelo sustentável para descarte de resíduos.

\section{Referências}

Aguiar, E. M. de. (1993) Racionalização da operação de sistemas de coleta e transporte de resíduos sólidos domiciliares para cidades de pequeno e médio porte. Tese (Doutorado) - Escola Politécnica, Universidade de São Paulo, São Paulo.

Bradley, M. Lang, P. (1994) Measuring Emotion: The Self-Assessment Maninkin and Semantic Differential- Journal of Behavior Therapy and Experimental Psychiatry, 49-59

Brasil, A. M. Santos, F. (2004) Equilíbrio Ambiental e Resíduos na sociedade moderna. São Paulo: FAARTE Editora, pp. 47 - 53, (ISBN 85-98847-01-1).

Brito, R., Queirós JR, W., Fernandes, M., Bonifácio, B. Fernandes, P., (2015) " MACteaching: Utilizando um Jogo para Apoio ao Ensino do Método de Avaliação de Comunicabilidade" In: XXVII Simpósio Brasileiro de Informática na Educação, 2016, Uberlandia, 2016. p. 180-189.

Li, J., Chen, Y. (2013) An Analysis of the Influence of Visual Perception Characteristics to the Usability Design of Infants Application Interface, Trans Tech Publications,Switzerland.

Trindade, N., A., D., (2011) Consciência Ambiental: Coleta Seletiva e Reciclagem no Ambiente Escolar. Cachoeirinha-RS: FASB, 2007. - disponível em: http://www.conhecer.org.br/enciclop/2011a/humanas/consciencia\%20ambiental.pdf acesso em: 01/07/2017 